EVS25

Shenzhen, China, Nov 5-9, 2010

\title{
Key Parameters Investigation on Small Cycle Fuel Injection Quantity for a Diesel Engine Electronic Unit Pump System
}

\author{
Liyun Fan ${ }^{1}$, Bingqi $\operatorname{Tian}^{1}$, and Xiuzhen $\mathrm{Ma}^{1}$ \\ ${ }^{1}$ College of Power and Energy Engineering, Harbin Engineering University,Harbin, Heilongjiang, China \\ E-mail: fanly_01@163.com, tianbingqi @163.com, maxiuzhen@hrbeu.edu.cn
}

\begin{abstract}
In order to meet the China's PHASE III and IV emission legislations, Electronic Unit Pump (EUP) system has been used by many diesel engine companies in China. The fluctuation on small cycle fuel injection quantity (SCFIQ) has great influence on the stability at small load operation of the diesel engine. A numerical model of the EUP system was built in the AMESim environment for the purpose of computing and analyzing the fluctuation on the SCFIQ. The influence of the different parameters on small cycle fuel injection quantity fluctuation (SCFIQF) has been obtained by the AMESim simulation model. By computing and analyzing, the quantitative percentage index of the influence on SCFIQ caused by different parameters also has been obtained. The influence percentage of injector characteristic parameters is from $35.8 \%$ to $60.8 \%$, plunger characteristic parameters is from $20.3 \%$ to $34.8 \%$, low pressure supply fuel characteristics is from 0 to $20.2 \%$, and valve characteristic parameters is form $6.6 \%$ to $23.2 \%$ with the revolution range from $500 \mathrm{r} / \mathrm{min}$ to $1300 \mathrm{r} / \mathrm{min}$. Based on the design of experiment (DOE) method, take the without interaction and interaction into consideration, the correlations of SCFIQ and different factors have been obtained and analyzed. Copyright Form of EVS25.
\end{abstract}

Keywords: EUP, SCFIQ, quantitative percentage index, correlation

\section{Introduction}

The China's PHASE III and IV emission legislations are equivalent to Euro III and IV emission legislations. All new diesel engines for highway application should be equipped with electronic controlled fuel injection systems to meet the new emission legislations.

Although it is possible for Chinese engine manufacturers to apply existing electronic controlled fuel injection systems such as Common Rail(CR) [1] [2] [3], the implementation is often difficult due to availability, cost and maintenance factors in Chinese market.
So a new electronic controlled fuel injection system is desired for which can provide low cost, less maintenance and good adaptation to existing engines. The EUP is such a system with a solenoid valve replacing the traditional mechanical fuel injection system.

The EUP system consists of the high pressure pump assembly, the fuel injectors, the Electronic Control Unit (ECU) and some sensors, etc. A supply pump draws fuel from tank and feeds it to the high pressure pump. Similar mechanical unit pump, a plunger driven by a cam acts as the pumping element. A solenoid located above the plunger determines when and how much the fuel is injected. With the solenoid is closing, the fuel pressure is building up, then the fuel injection 
begins. With the opening of the solenoid, the fuel pressure decays, then the fuel injection finishes. ECU receives signals such as the pressure and the engine speed from sensors, after analyzing and processing, sends out the control instruction to control the solenoid valve. The foremost advantage of the EUP is that it can be easily installed on the existing engines which had equipped with mechanical unit pumps, can reduce the harmful emission and improve the economy of diesel engine.

This paper mainly concerned with the quantitative and correlative analysis on the SCFIQF characteristics of EUP system.

\section{Numerical Modeling of EUP System}

EUP is a complex system assembling electric field, magnetic field, mechanical movement and flow field. The interaction of these fields is presented in Fig.1 [4] [5] [6].

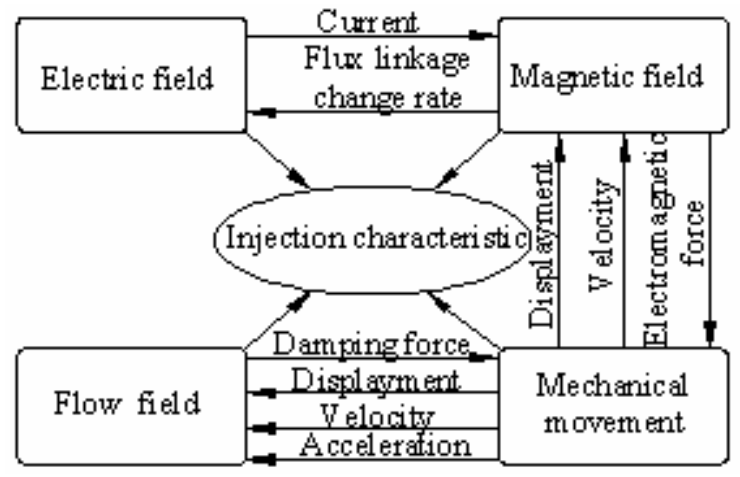

Figure 1: The interaction of fields

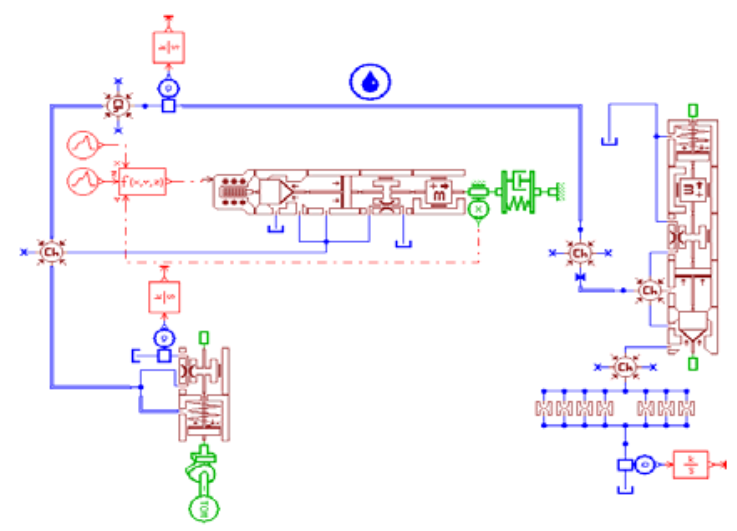

Figure 2: EUP AMESim simulation model

Fields couple together by their control equation and the interaction of variables. The parameters of each field will influence the final injection characteristics directly or indirectly via wave equation in fuel line. Therefore, the characteristic parameters of injection system can be calculated by the electromagnetic coupled equation, mechanical motion equation, flow characteristics equation and wave equation of high pressure fuel line. This paper constructed the calculation modeling in AMESim environment shown as Fig.2 [7] [8] [9].

\section{Quantitative Analysis of SCFIQF}

SCFIQ is determined by key parameters of the EUP, such as supply fuel pressure, cam velocity, nozzle flow coefficient, injector opening pressure, injector needle lift, valve matching clearance, plunger matching clearance, anchor residual clearance, valve lift, etc. The key parameter's machining accuracy and variation in service period influence SCFIQF.

The percentage quantitative indexes of the influence on the SCFIQF caused by different parameters, namely, the influence percentage of different characteristic parameters on SCFIQF is obtained according to the absolute values of SCFIQF at different revolutions resulted from analyzing different characteristic parameters of the fuel injection system.

As shown in Fig.3, the revolution changing from $500 \mathrm{r} / \mathrm{min}$ to $1300 \mathrm{r} / \mathrm{min}$ while the injection pulse width is 2 cam angles. The cam velocity and injector opening pressure are two main key parameters of the SCFIQF. The influence percentage of cam velocity and injector opening pressure are from $20.2 \%$ to $34.3 \%$ and from $25.9 \%$ to $49.8 \%$ respectively, both decreasing with the rise of revolution. Because absolute time of per unit cam angle at low revolution is longer than that at high revolution. Thus, effective time of cam velocity at low revolution is longer and cam velocity's influence on SCFIQF is more obvious. On the other hand, fuel injection delay time and effective time are determined by injector open pressure. As a result, the length of fuel injection delay time is determined by the speed of fuel pressure establishment in high pressure fuel pipe. When the fuel quantity supplied by plunger at high revolution is large in unit absolute time, the fuel pressure establishment in high pressure fuel pipe is fast and the delay time of injector needle opening is short. Therefore, the variation of injector open pressure has little influence on SCFIQF. Inverse the fuel pressure establishment at low revolution is slow in high pressure fuel pipe, for this reason, the delay time of injector needle opening is longer. Influence of injector open pressure is large at low revolution. 
The influence percentage of supply fuel pressure is from 0 to $20.2 \%$, which is increasing with the rise of revolution. The supply fuel pressure determines fuel suction's insufficient degree of the EUP system. When the cam revolution is high, absolute effective time of the fuel supply is short and the supply fuel pressure's influence on the insufficient degree of fuel supply is more remarkable, as a result, the influence percentage of the fuel supply pressure on the SCFIQF increases with the rise of revolution.

The influence percentage of injector needle lift is from 0 to $16.5 \%$, it reached the highest value when revolution is $1000 \mathrm{r} / \mathrm{min}$, and decreases with the revolution rising or reducing from $1000 \mathrm{r} / \mathrm{min}$. The reason is when the revolution is low, fuel pressure is low and lift of the injector needle is small, so fuel injection quantity is small or even is zero. But at high revolution, the effective injection time is short, so the fuel injection quantity is also small at this case. Thus, when the revolution is $1000 \mathrm{r} / \mathrm{min}$, fuel injection quantity is larger, so influence percentage of the injector needle lift reached the largest value.

The influence percentage of nozzle flow coefficient on SCFIQF is from $2.6 \%$ to $10.5 \%$, its influence reached the peak value when the revolution is $900 \mathrm{r} / \mathrm{min}$, and decrease with the revolution rising or reducing from $900 \mathrm{r} / \mathrm{min}$. because the nozzle flow coefficient is characterization of fuel injection quantity at specific pressure, so its influence increase with the increase of fuel injection quantity, when the revolution is $900 \mathrm{r} / \mathrm{min}$, the fuel injection quantity reached the peak value, then, the influence of the nozzle flow coefficient reached the peak value at the same time.

The influence percentage of anchor residual clearance, and valve lift are from $0.1 \%$ to $6.8 \%$ and from $6.4 \%$ to $16.4 \%$ respectively, both of them reached the minimum value when the revolution is at $1000 \mathrm{r} / \mathrm{mim}$, and increase with the revolution rising or reducing from $1000 \mathrm{r} / \mathrm{min}$. The reason is determined by the key parameters complex effect. The influence percentage of valve matching clearance and plunger matching clearance are from $0.1 \%$ to $0.4 \%$ and from 0 to $0.5 \%$ respectively. When fuel's leaking time in the both clearances is long, leakage is large at low revolution. However, there is high fuel pressure at high revolution, so there also have large leakage. For this reason, the two clearances have smaller influence at $900 \mathrm{r} / \mathrm{min}$ and $1000 \mathrm{r} / \mathrm{min}$ than at others.

Characteristic parameters are divided into four categories according to the category of components they belong to. The percentages of each category of SCFIQF are shown in Fig. 4, operating conditions are the same as above. The influence percentage of the injector characteristic parameters declines from $60.8 \%$ to $35.8 \%$, the influence percentage of the plunger characteristic parameters decreases from $34.8 \%$ to $20.3 \%$, the influence percentage of the low pressure supply fuel system characteristic parameters increases from 0 to $20.2 \%$, and the influence percentage of the valve characteristic parameters range from $6.6 \%$ to $23.2 \%$. The conclusion could be drawn from the mentioned above, for maintaining the injection coherence, it is very important to control the stability of injector opening pressure and nozzle flow coefficient. Influence of cam velocity is the most important parameter in plunger characteristic parameters, which can be reduced by enhancing the supporting stiffness of camshaft and improving the precision of shaft coupling. Solenoid valve characteristic parameters mainly influence the effective fuel supply pulse width of the EUP, which can be avoided by feedback control of the electronic control system. The influence extent of low pressure fuel supply system can be reduced by improving the pressure stability of fuel supply pump, cleanliness of filter and stability of relief valve.

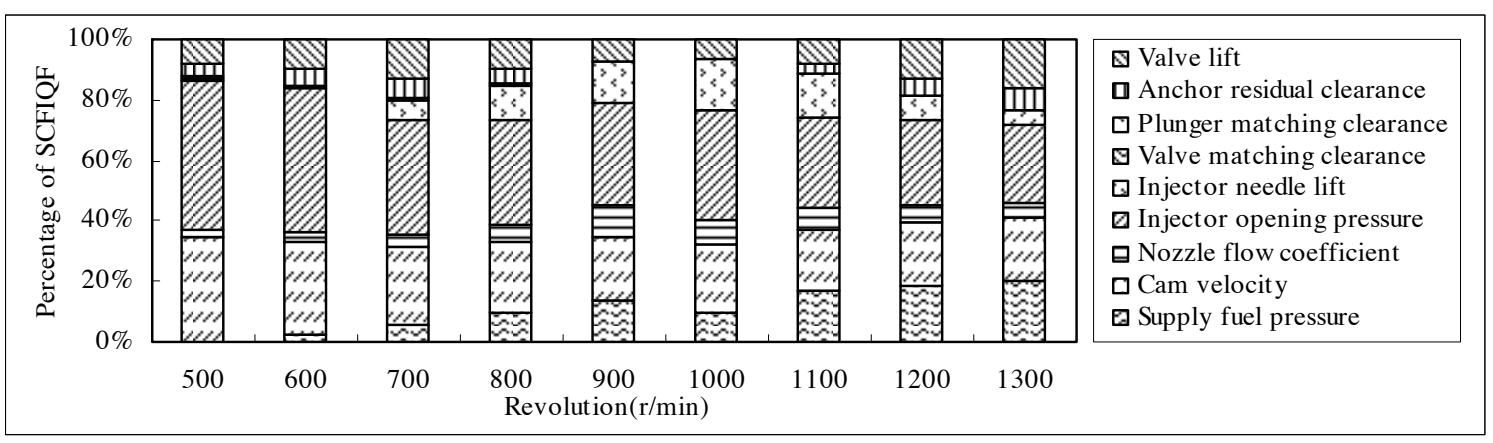

Figure 3: Influence percentage of different characteristic parameters on the SCFIQF 


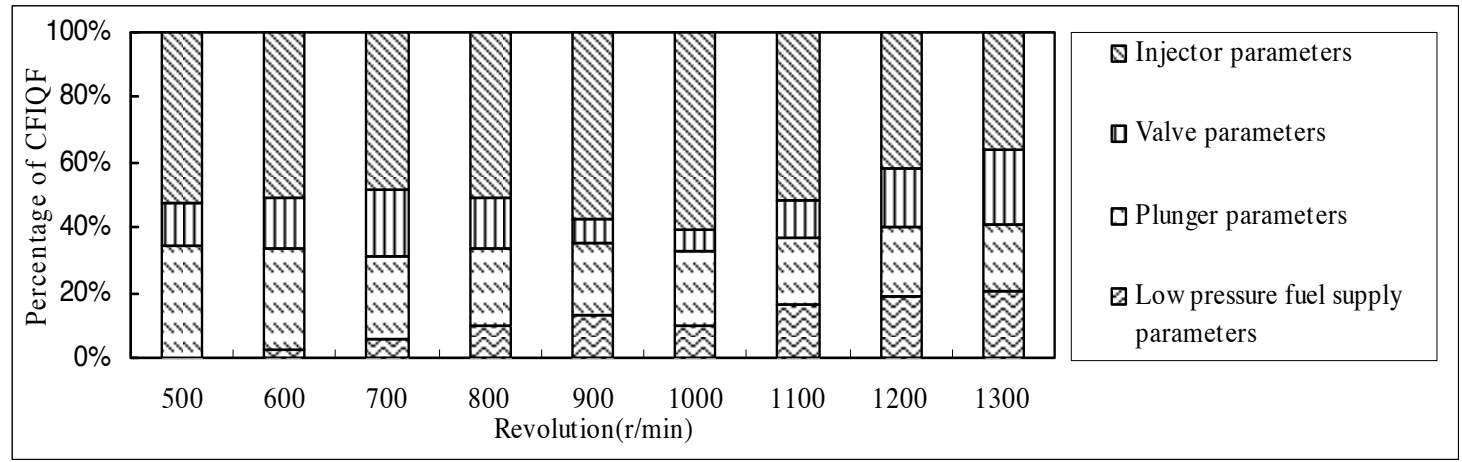

Figure 4: Influence percentage of different components characteristic parameters on the SCFIQF

\section{Correlation Analysis of SCFIQ}

SCFIQF of EUP system is determined by many characteristic parameters, and it is clearly that the effects caused by these characteristic parameters are complicated according to the conclusion above, but correlation between characteristic parameters and SCFIQ had not been studied. This section will analyze the correlation of parameters and the SCFIQ by using the design of experiment (DOE) method at MODDE environment [10].

Fig. 5 presents the correlation between different characteristic parameters and the SCFIQ at different revolution without respecting their interaction. The correlation between injector opening pressure and SCFIQ is largest (Negative correlation represents the SCFIQ decreases with the increase of influence factor), and it declines with the rising of revolution. The correlation between cam velocity and SCFIQ is also very significant, it doesn't have obviously change with the increase of revolution. Absolute value of correlations between supply pressure, valve lift (negative correlation), anchor residual clearance (negative correlation), nozzle flow coefficient and SCFIQ all increase with the rise of revolution. Correlation absolute value between injection needle lift and SCFIQ at high revolution is larger than that at low revolution. Correlations of valve matching clearance and plunger matching clearance with SCFIQ are small, and nearly have no obvious variation. With the variation of revolution, correlations change between different characteristic parameters and SCFIQ are the same as changes of SCFIQF percentage influenced by different characteristic parameters.

Correlation analysis in Fig.5 presents positive correlation and negative correlation both exist between characteristic parameters and SCFIQ, but the effect of interaction factors are neglected in the analysis. Therefore considering factors interaction, smaller correlation coefficient such as correlation of valve matching clearance and plunger matching clearance with SCFIQ will be neglected, so as to simplify the DOE model. Taking interaction into consideration, correlations of 7 parameters with SCFIQ are analyzed, by using central composite face (CCF) method in MODDE environment.

Fig.6 presents analysis results of the correlations between 35 factors and SCFIQ with interaction effects respected. It is evident that, not only interaction factor of parameter itself, but also interaction factors between different parameters have correlation with SCFIQ, and the correlation shows different regularity with the variation of revolution. Interaction factors have obvious effects at high revolution. As shown in Fig.6, the 11th is interaction factor of injector opening pressure with injector opening pressure. The correlation coefficient of it is negative when the revolution is $500 \mathrm{r} / \mathrm{min}$ and $900 \mathrm{r} / \mathrm{min}$, the value is -1.05 and 0.04 respectively, but when revolution is 1300 $\mathrm{r} / \mathrm{min}$, the correlation coefficient is positive, and its value is 0.002 . It is quite clear that positive correlation and negative correlation of interaction factors change with the variation of revolution. Similarly, the correlation of the 8th, 9th, 10th, 12th, 13th,14th, 15th, 16th, 19th, 21st, 22nd, 23rd,24th, 26th and 28th also change with the variation of revolution. Correlation coefficients of 20th, 25th, 29th, 32nd, 34th and 35th are all zero at three revolutions. Consequently, SCFIQ is a complicated representation determined by various characteristic parameters. 


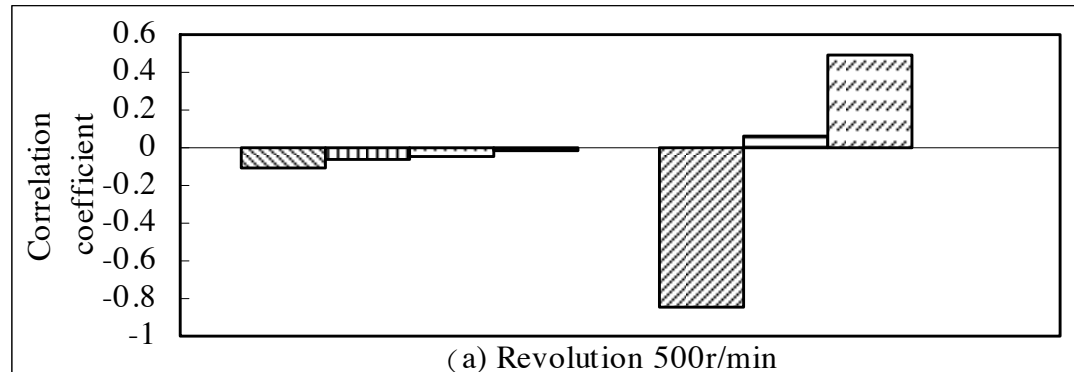

$\$$ Valve lift

巴 Anchor residual clearance

$\checkmark$ Plunger matching clearance

$\checkmark$ Valve matching clearance

๑ Injector needle lift

Injector opening pressure

日 Nozzle flow coefficient

口 Cam velocity

은 Supply fuel pressure

(a) Revolution 500r/min

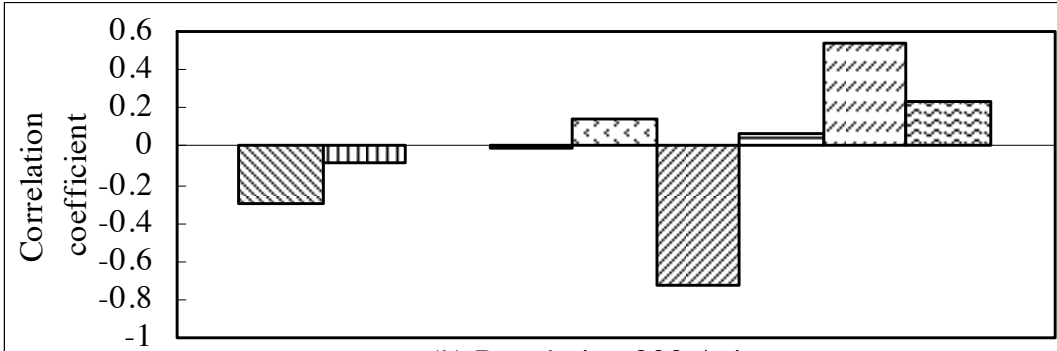

$\checkmark$ Valve lift

D Anchor residual clearance

$\square$ Plunger matching clearance

Valve matching clearance

$\square$ Injector needle lift

口 Injector opening pressure

日 Nozzle flow coefficient

口 Cam velocity

圆 Supply fuel pressure

(b) Revolution $900 \mathrm{r} / \mathrm{min}$

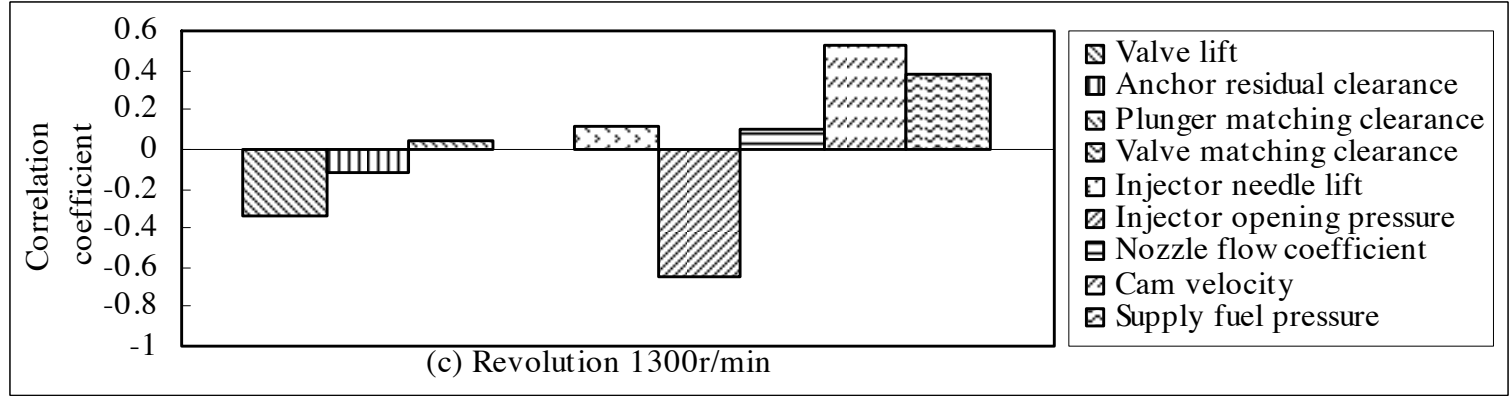

Figure 5: Correlation between different factors and SCFIQ
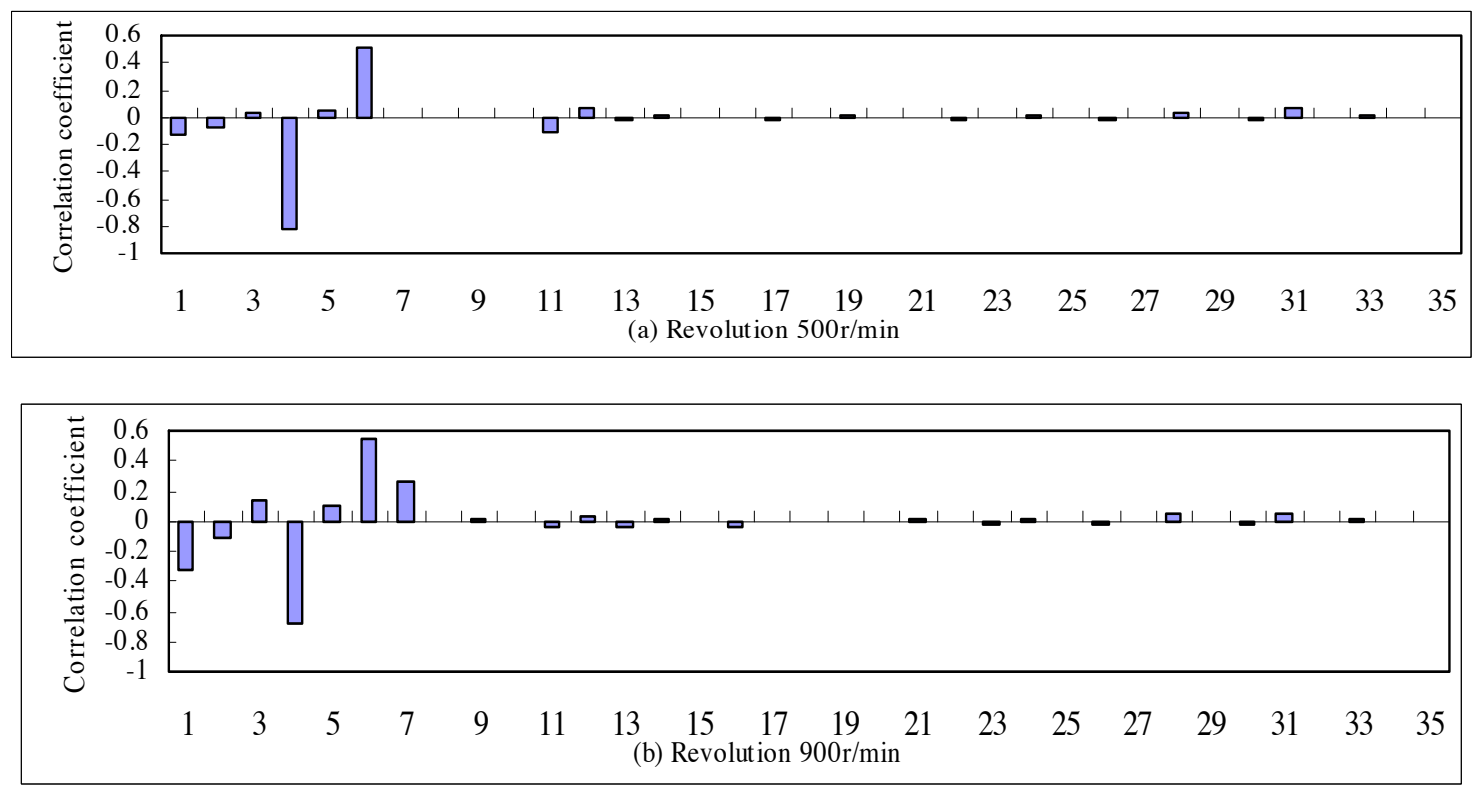


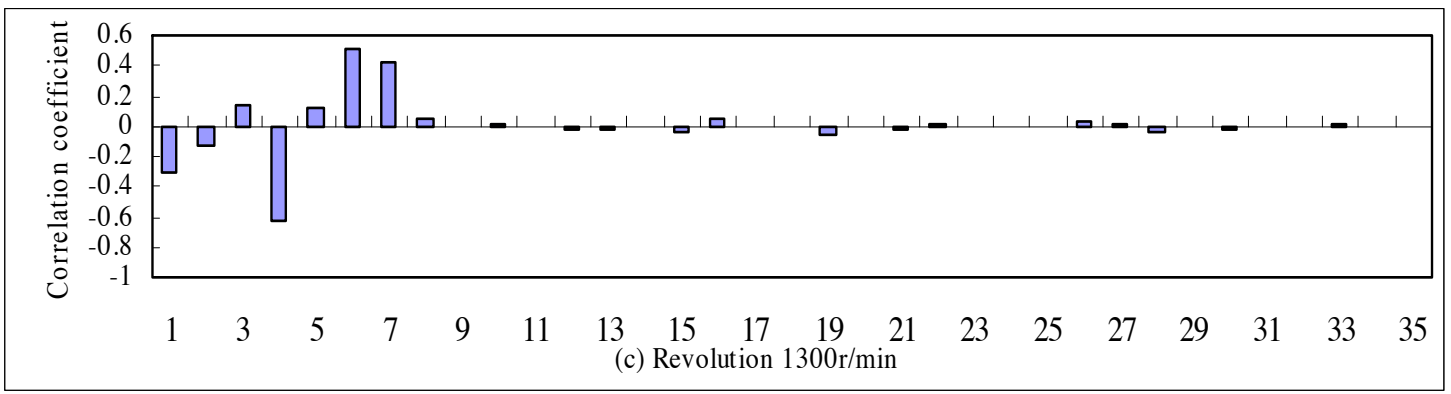

Figure 6: Correlation between different factors and CFIQ at interaction condition

The interaction factors according to the serial number in Fig.7 are listed at follow (* shows the common effect of two factors).

1 valve lift, 2 anchor residual clearance, 3 injector needle lift, 4 injector opening pressure, 5 nozzle flow coefficient, 6 cam velocity, 7 supply fuel pressure, 8 valve lift * valve lift, 9 anchor residual clearance * anchor residual clearance, 10 injector needle lift * injector needle lift, 11 injector opening pressure * injector opening pressure, 12 nozzle flow coefficient $*$ nozzle flow coefficient, 13 cam velocity * cam velocity, 14 supply fuel pressure * supply fuel pressure, 15 valve lift * anchor residual clearance, 16 valve lift * injector needle lift, 17 valve lift $*$ injector opening pressure, 18 valve lift * nozzle flow coefficient, 19 valve lift * cam velocity, 20 valve lift * supply fuel pressure, 21 anchor residual clearance * injector needle lift, 22 anchor residual clearance * injector opening pressure, 23 anchor residual clearance * nozzle flow coefficient, 24 anchor residual clearance * cam velocity, 25 anchor residual clearance * supply fuel pressure, 26 injector needle lift * injector opening pressure, 27 injector needle lift * nozzle flow coefficient, 28 injector needle lift * cam velocity, 29 injector needle lift $*$ supply fuel pressure, 30 injector opening pressure * nozzle flow coefficient, 31 injector opening pressure * cam velocity, 32 injector opening pressure * supply fuel pressure, 33 nozzle flow coefficient $*$ cam velocity, 34 nozzle flow coefficient * supply fuel pressure, 35cam velocity * supply fuel pressure

\section{Conclusions}

The quantitative percentage index of the influence of different parameters on SCFIQF is obtained by AMESim simulation model. The influence percentage of injector characteristic parameters decline from $60.8 \%$ to $35.8 \%$, the influence percentage of the plunger characteristic parameters decreases from $34.8 \%$ to $20.3 \%$, the influence percentage of the low pressure supply fuel system characteristic parameters increases from 0 to $20.2 \%$, and the influence percentage of the valve characteristic parameters range from $6.6 \%$ to $23.2 \%$ with the revolution rises from $500 \mathrm{r} / \mathrm{min}$ up to $1300 \mathrm{r} / \mathrm{min}$.

Based on DOE method, correlation coefficient between different characteristic parameters and SCFIQ are obtained. The conclusion shown that SCFIQF is complicated representation determined by various characteristic parameters, not only parameter's single factor with SCFIQ have correlation, also parameter's interaction factor with SCFIQ have correlation, among which the most significant influence is caused by injector opening pressure and cam velocity.

\section{Acknowledgements}

The authors gratefully acknowledge the National Natural Science Foundation of China (NSFC 50909024), the Science Fund of State Key Laboratory of Automotive Safety and Energy (KF10102), the Fundamental Research Funds for the Central Universities (HEUCF110301), the Program for New Century Excellent Talents in University (NCET) and the Education Ministry Combination of Production, Education and Scientific Research Project of Guangdong province (2009A090100050).

\section{References}

[1] Miyaki, M., Fujisawa, H., Masuda, A., et al. Development of New Electronically Controlled Fuel Injection System ECD-U2 for Diesel Engines, SAE paper 910252, 199.

[2] Guerrassi, N., Dupraz. P., A Common Rail Injection System for High Speed Direct Injection Diesel Engines, SAE paper 980803, 1998.

[3] Flaig, U., Ploach, W., and Ziegler, G., Common Rail System for Passenger Car DI Diesel Engines, Experiences with Applications for Series Production Projects, SAE paper 1999-01-0191, 1999.

[4] Li, J., Zhang, K. X., Li, J.Q., et al. Injection Control Algorithm for an Electronic Unit-Pump, Journal of Tsinghua University, 2005, 45 (11), p. 1526-1529. 
[5] Yang, M.G., Sorenson, S. C., Modeling of the Dynamic Processes in an Electronic Diesel Fuel Injection System, SAE Paper 9202400, 1992.

[6] Xia, S.G., Performance optimization of New electronic fuel injection system, Beijing, Tsinghua university, 2000

[7] Hao, S.G., Research on Electromagnetic, Mechanical and Hydraulic Characteristics of Solenoid Valve for Electronically Controlled Unit Pump, Beijing, Tsinghua University,2003.

[8] Fan L.Y., Zhu Y.X., Long W.Q., et al. A Characteristic Study of Electronic In-line Pump System for Diesel Engines, SAE Paper 2008-01-0943, 2008.

[9] IMAGINE SA. AMESim User Manual, Version 4.2, September 2004.

[10] Umetrics AB MODDE Users Guide, Version 7.0, August 2003.

\section{Authors}

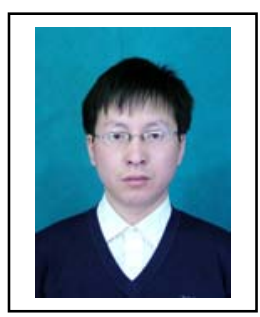

Associate professor. Liyun Fan

Affiliation: College of Power and

Energy Engineering, Harbin

Engineering University

Mailing Address: Room 1212,

College of Power and Energy

Engineering,Harbin Engineering

University,Harbin,HLJ,P.R. China

Tel: 86-0451-82568316-8203

Email: fanly_01@163.com

\section{PH.D. candidate. Bingqi Tian}

Affiliation: College of Power and

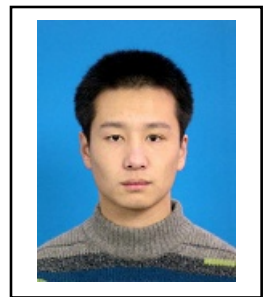

Energy Engineering, Harbin

Engineering University

Mailing Address: Room 1201,

College of Power and Energy

Engineering,Harbin Engineering

University,Harbin,HLJ,P.R. China

Tel:86-0451-82568316

Email: tianbingqi @163.com 